\title{
Trifurcated graft replacement of the aortic arch: State of the art
}

\author{
Gilbert H. L. Tang, MD, MSc, MBA, Masashi Kai, MD, Ramin Malekan, MD, \\ Steven L. Lansman, MD, PhD, and David Spielvogel, MD
}

Objective: To review the contemporary practice in total arch replacement (TAR) by using the trifurcated graft
technique. Methods: The evolution of the trifurcated graft technique in total arch replacement is described. Axillary artery perfusion with antegrade cerebral perfusion (ACP) is routinely performed, with systemic deep hypothermia based on the anticipated interval of lower body ischemia. Cerebral oxygen saturation is monitored and bilateral ACP (BACP) is performed if the adequacy of collateral circulation is questioned. Potential advantages and disadvantages of unilateral ACP (UACP) vs BACP are discussed.

\begin{abstract}
Results: The advantage of the trifurcated graft technique in TAR is that it facilitates the creation of an "elephant trunk" in the proximal arch, making the operation technically easier and avoiding the risk of recurrent laryngeal nerve injury. The technique is also versatile in a variety of aortic arch anatomies and pathologies, while enabling continuous ACP without hypothermic circulatory arrest for cerebral protection. UACP during TAR is acceptable for shorter intervals ( $<30-40$ minutes) if combined with moderate hypothermia. BACP should be considered for prolonged ACP interval or if left cerebral oxygenation is inadequate during UACP.
\end{abstract}

Conclusions: The trifurcated graft technique is a versatile method in TAR that can be applied to a diverse range of aortic anatomies, pathologies and hybrid arch procedures, with concomitant or staged endovascular options. $\mathrm{UACP}$ or BACP and lower body ischemia can be performed without adding significant complexity to the procedure, while conferring maximal cerebral, spinal, and lower body protection. (J Thorac Cardiovasc Surg 2015;149:S55-8)

In September 1999, we initiated a series with a new approach to total aortic arch replacement (TAR) that uses a trifurcated graft to address some deficiencies of the standard Carrel patch technique. Among these deficiencies, a critical problem was that the Carrel patch and the origins of the brachiocephalic vessels were often severely involved with atherosclerotic disease, posing an important threat for cerebral embolization. We were quickly impressed by the simplicity and versatility of the trifurcated graft method and reported on our first series of 22 patients in $2002 .{ }^{1}$ Initially, the brachiocephalic anastomoses were constructed during a single interval of deep hypothermic circulatory arrest (HCA), followed by antegrade selective cerebral perfusion (ACP) through the trifurcated graft. ${ }^{1}$ With experience, the technique was modified, with various strategies of ACP through the trifurcated graft, permitting the entire

From the Section of Cardiothoracic Surgery, Department of Surgery, Westchester Medical Center, New York Medical College, Valhalla, NY.

Disclosures: Authors have nothing to disclose with regard to commercial support.

Read at The American Association for Thoracic Surgery Aortic Symposium, New

York, New York, April 24-25, 2014.

Received for publication April 23, 2014; accepted for publication July 7, 2014; available ahead of print Aug 28, 2014.

Address for reprints: David Spielvogel, MD, Cardiothoracic Surgery, Westchester Medical Center, 100 Woods Rd, Macy 114W, Valhalla, NY 10595 (E-mail: SpielvogelD@WCMC.com).

$0022-5223 / \$ 36.00$

Copyright (C) 2015 by The American Association for Thoracic Surgery

http://dx.doi.org/10.1016/j.jtcvs.2014.07.038 procedure to be performed without any $\mathrm{HCA}$ and with only a brief period of lower body ischemia (LBI), permitting more moderate cooling, earlier rewarming, and shorter cardiopulmonary bypass times. In addition, the risk of cerebral embolization was minimized with the trifurcated graft technique by avoiding the Carrel patch anastomosis altogether.

From 1999 through 2013, a total of 253 patients underwent TAR with the trifurcated graft method. The overall mortality was $7.1 \%$, with a stroke rate (permanent neurologic deficit [PND]) of $4.3 \%$ and a temporary neurological dysfunction (TND) frequency of 5.1\% (Unpublished data, 2014).

The method has become standardized. Unless contraindicated, axillary artery perfusion is used, and the degree of systemic cooling is based on the anticipated interval of LBI. Spinal cord and visceral injury are rare in arch surgery with HCA but must be safeguarded against if long periods of moderate hypothermic ACP are used. ${ }^{2}$ When LBI time exceeded 60 minutes, Kamiya and colleagues ${ }^{3}$ found a significant increase in paraplegia $(18 \%)$ at moderate hypothermia $\left(25^{\circ} \mathrm{C}-28^{\circ} \mathrm{C}\right)$ relative to the $0 \%$ seen at lower temperatures $\left(20^{\circ} \mathrm{C}-24^{\circ} \mathrm{C}\right)$. Experimental data suggest that significant spinal and multiorgan injury occur with LBI greater than 90 minutes and $\mathrm{ACP}$ at $28^{\circ} \mathrm{C}$, with prolonged LBI being an independent predictor of short- and longterm mortality. Importantly, even experimental animals without overt paraplegia had significant histologically 


\section{Abbreviations and Acronyms \\ $\mathrm{ACP}=$ antegrade selective cerebral perfusion \\ $\mathrm{BACP}=$ bilateral antegrade cerebral perfusion \\ HCA = hypothermic circulatory arrest \\ LBI = lower body ischemia \\ PND = permanent neurologic deficit \\ TAR $=$ total aortic arch replacement \\ $\mathrm{TND}=$ temporary neurological dysfunction \\ $\mathrm{UACP}=$ unilateral antegrade cerebral perfusion}

detectable spinal cord damage. ${ }^{2}$ Safe ischemic intervals for the spinal cord at various temperatures were identified as follows: 20 minutes at normothermia $\left(37^{\circ} \mathrm{C}\right), 50$ minutes at mild hypothermia $\left(32^{\circ} \mathrm{C}\right), 75$ minutes at moderate hypothermia $\left(28^{\circ} \mathrm{C}\right)$, and 120 minutes at deep hypothermia $\left(20^{\circ} \mathrm{C}\right){ }^{4}$ Total body protection thus depends not only on cerebral protection but also on a sound strategy to protect the spinal cord and lower body. Prolonged LBI requires that TAR be performed either with moderate to deep hypothermia or with distal lower body perfusion to minimize spinal cord and visceral injury. Two methods for lower body perfusion can help avoid LBI: retrograde perfusion through the femoral artery or antegrade perfusion through a sidearm graft incorporated with the arch replacement graft.

Deep hypothermia $\left(18^{\circ} \mathrm{C}-22^{\circ} \mathrm{C}\right)$ is induced while the proximal reconstruction takes place. The need for a sinotubular repair, Bentall procedure, or valve-sparing root replacement determines the rate of cooling before lower body circulatory arrest. Epiaortic scanning is used to assess the degree of intraluminal atheromatous disease or thrombus before crossclamping of the aorta. Flow is reduced to 6 to $8 \mathrm{~mL} / \mathrm{kg}$, initiating unilateral antegrade cerebral perfusion (UACP), and the brachiocephalic arteries are occluded, beginning sequentially with the innominate artery. Direct arterial pressure monitoring ensures that hyperperfusion of the right cerebral hemisphere does not occur. Cerebral saturation is monitored with near-infrared spectroscopy, with particular attention paid to the left side, where a significant drop $(>20 \%)$ relative to the right might signify inadequate collateral circulation and the need for bilateral antegrade cerebral perfusion (BACP). ${ }^{5}$ The 3 brachiocephalic vessels can be anastomosed to the trifurcated graft in less than 30 minutes, at which time BACP (10-12 mL/kg; mean arterial pressure of $40-60 \mathrm{~mm} \mathrm{Hg}$ ) through the trifurcated graft can commence through the axillary artery, with the perfusate temperature allowed to drift upward.

The potential advantages and disadvantages of BACP relative to UACP in TAR are summarized in Table 1. A recent review by Luehr and colleagues ${ }^{4}$ detailed differences between the 2 strategies, but several large studies are worth discussion (Table 2). Krähenbühl and colleagues ${ }^{6}$ compared UACP with BACP among 280 patients and found no differences in mortality, TND, and PND, but the BACP group had better midterm quality of life scores. Zierer and colleagues ${ }^{7}$ compared UACP with $\mathrm{BACP}$ at $28^{\circ} \mathrm{C}$ to $30^{\circ} \mathrm{C}$ in 184 propensity-matched patients who underwent TAR with mild hypothermia $\left(30^{\circ} \mathrm{C}\right)$. A trend toward higher PND $(2.2 \%$ vs $9.7 \% ; P=.06)$ was found in the BACP group, despite no differences in early mortality and TND. Angeloni and colleagues ${ }^{8}$ compared UACP and BACP in a meta-analysis of more than 5000 patients (28 studies) and found no difference in early mortality, TND, and PND; however, higher temperature and longer HCA time were associated with higher mortality and PND. In the German Registry for Acute Aortic Dissection type A study, ${ }^{9}$ there was no difference in mortality or PND between UACP and BACP; however, cerebral perfusion flows greater than $600 \mathrm{~mL} / \mathrm{min}$ and pressures greater than $60 \mathrm{~mm} \mathrm{Hg}$ were associated with reduced PND but not mortality, and cerebral perfusion greater than 60 minutes was associated with increased mortality regardless of strategy. Papantchev and

TABLE 1. Advantages and disadvantages of UACP versus bilateral antegrade cerebral perfusion in aortic arch surgery

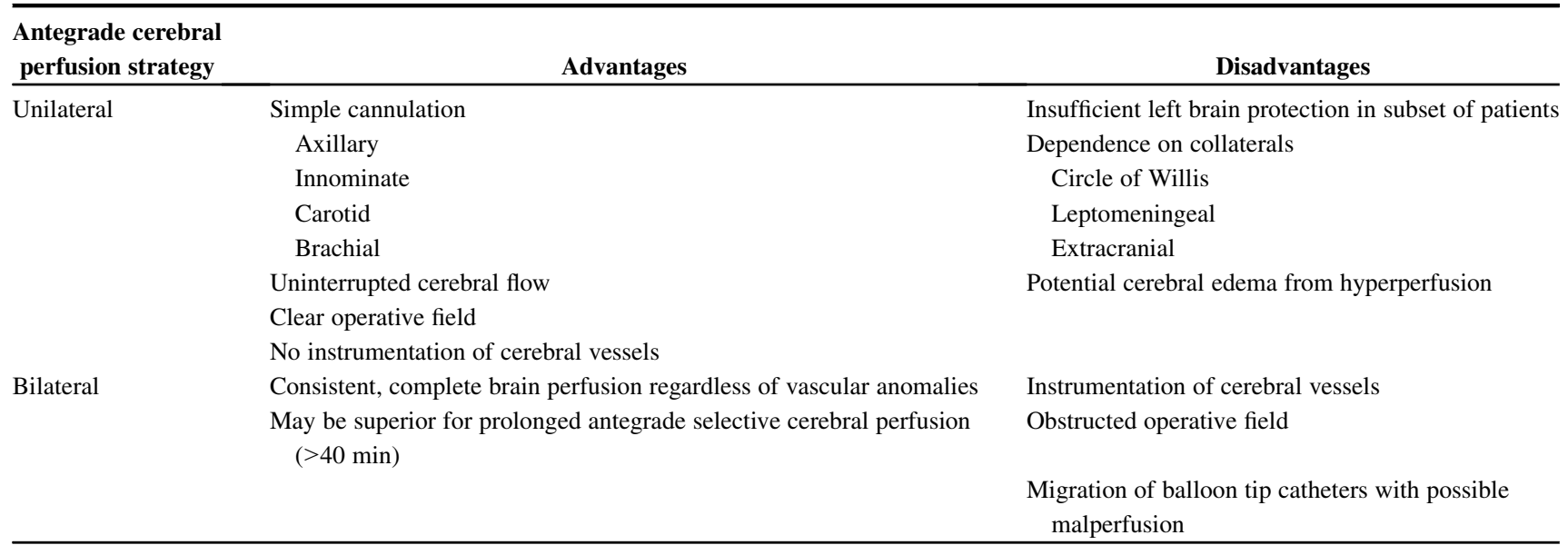


TABLE 2. Select studies comparing unilateral antegrade cerebral perfusion with bilateral antegrade cerebral perfusion in aortic arch surgery

\begin{tabular}{|c|c|c|c|c|c|}
\hline & Krähenbühl $^{6}$ & Krüger $^{9}$ & Zierer $^{7}$ & Zierer $^{7}$ & Angeloni $^{8}$ \\
\hline Centers & Bern, Switzerland & 44 centers, Germany & $\begin{array}{l}\text { Frankfurt, } \\
\text { Bad Neustadt, } \\
\text { Germany }\end{array}$ & $\begin{array}{l}\text { Frankfurt, } \\
\text { Bad Neustadt, } \\
\text { Germany }\end{array}$ & $\begin{array}{l}28 \text { studies, }>30 \\
\text { centers worldwide }\end{array}$ \\
\hline Period & $2004-2007$ & 2006-2009 & 2010-2012 & 2010-2012 & $1986-2009$ \\
\hline Analysis & Retrospective & Retrospective & $\begin{array}{c}\text { Retrospective, } \\
\text { propensity } \\
\text { matching }\end{array}$ & $\begin{array}{c}\text { Retrospective, } \\
\text { propensity } \\
\text { matching }\end{array}$ & Meta-analysis \\
\hline Aortic surgery & $\begin{array}{c}\text { Hemiarch, total } \\
\text { arch; } 38 \% \\
\text { dissection }\end{array}$ & $\begin{array}{l}\text { Hemiarch, total arch; } \\
100 \% \text { dissection }\end{array}$ & Hemiarch, total arch & Total arch & $\begin{array}{l}\text { Hemiarch, total } \\
\text { arch }(\sim 25 \%) ; \\
\sim 25 \% \text { dissection }\end{array}$ \\
\hline Exclusion & & & Dissection & Dissection & \\
\hline $\mathrm{UACP}(\mathrm{N})$ & 118 & 628 & 246 & 91 & 1505 \\
\hline Systemic temperature & $<24^{\circ} \mathrm{C}$ bladder & NA & $30^{\circ} \mathrm{C} \pm 2^{\circ} \mathrm{C}$ rectal & $30^{\circ} \mathrm{C} \pm 2^{\circ} \mathrm{C}$ rectal & NA \\
\hline ACP temperature & $18-20^{\circ} \mathrm{C}$ & $\begin{array}{c}<15^{\circ} \mathrm{C}, 14 \% ; 15^{\circ} \mathrm{C}-20^{\circ} \mathrm{C} \\
21 \% ; 21^{\circ} \mathrm{C}-25^{\circ} \mathrm{C}, 23 \% \\
26^{\circ} \mathrm{C}-30^{\circ} \mathrm{C}, 17 \% \\
>30^{\circ} \mathrm{C}, 25 \%\end{array}$ & $28^{\circ} \mathrm{C}-30^{\circ} \mathrm{C}$ & $28^{\circ} \mathrm{C}-30^{\circ} \mathrm{C}$ & $23.7^{\circ} \mathrm{C}$ \\
\hline ACP flow & $0.8-1 \mathrm{~L} / \mathrm{min}$ & $820 \pm 436 \mathrm{~mL} / \mathrm{min}$ & $\begin{array}{r}0.9(\mathrm{LCC}), 1.1 \\
1.5 \mathrm{~L} / \mathrm{min}\end{array}$ & $\begin{array}{r}0.9(\mathrm{LCC}), 1.1 \\
1.5 \mathrm{~L} / \mathrm{min}\end{array}$ & NA \\
\hline $\mathrm{ACP}$ pressure $(\mathrm{mm} \mathrm{Hg})$ & $50-60$ & $66 \pm 32$ & $75-80$ & $75-80$ & NA \\
\hline ACP duration (min) & $28 \pm 12$ & $32 \pm 18$ & $41 \pm 19$ & $65 \pm 13$ & $31 \pm 12$ \\
\hline In-hospital/30-d mortality & $4.2 \%$ & $13.9 \%$ & $3.7 \%$ & $6.6 \%$ & $8.6 \%$ \\
\hline TND & $7.6 \%$ & NA & $4.9 \%$ & $6.6 \%$ & $7.1 \%$ \\
\hline PND & $7.6 \%$ & $10.0 \%$ & $2.0 \%$ & $2.2 \%$ & $6.5 \%$ \\
\hline $\mathrm{BACP}(\mathrm{N})$ & $\begin{array}{c}133 \text { (innominate, LCC); } \\
29 \text { (RA, LCC) }\end{array}$ & 453 & 246 & 93 & 3595 \\
\hline Systemic temperature & $<24^{\circ} \mathrm{C}$ bladder & NA & $30^{\circ} \mathrm{C} \pm 2^{\circ} \mathrm{C}$ & $30^{\circ} \mathrm{C} \pm 2^{\circ} \mathrm{C}$ & NA \\
\hline ACP temperature & $18^{\circ} \mathrm{C}-20^{\circ} \mathrm{C}$ & $\begin{array}{r}<15^{\circ} \mathrm{C}, 7 \% ; 15^{\circ} \mathrm{C}-20^{\circ} \mathrm{C}, \\
52 \% ; 21^{\circ} \mathrm{C}-25^{\circ} \mathrm{C} \\
27 \% ; 26^{\circ} \mathrm{C}-30^{\circ} \mathrm{C} \\
12 \% ;>30^{\circ} \mathrm{C}, 2 \%\end{array}$ & $28^{\circ} \mathrm{C}-30^{\circ} \mathrm{C}$ & $28^{\circ} \mathrm{C}-30^{\circ} \mathrm{C}$ & $23.1^{\circ} \mathrm{C}$ \\
\hline ACP flow & $\begin{array}{r}250-300 \mathrm{~mL} / \mathrm{min} \\
650 \mathrm{~mL} / \mathrm{min}\end{array}$ & $758 \pm 358 \mathrm{~mL} / \mathrm{min}$ & $1.4 \mathrm{~L} / \mathrm{min}$ & $1.4 \mathrm{~L} / \mathrm{min}$ & NA \\
\hline ACP pressure (mm Hg) & $50-60$ & $65 \pm 26$ & $75-80$ & $75-80$ & NA \\
\hline ACP duration (min) & $16 \pm 7 ; 43 \pm 17$ & $38 \pm 24$ & $43 \pm 21$ & $67 \pm 18$ & $31 \pm 19$ \\
\hline In-hospital/30-d mortality & $3.0 \% ; 6.8 \%$ & $15.9 \%$ & $4.5 \%$ & $8.6 \%$ & $9.2 \%$ \\
\hline TND & $8.2 \% ; 13.7 \%$ & NA & $4.1 \%$ & $5.4 \%$ & $8.8 \%$ \\
\hline PND & $6.0 \% ; 13.7 \% *$ & $11.0 \%$ & $5.7 \% \dagger$ & $9.7 \% \dagger$ & $6.1 \%$ \\
\hline
\end{tabular}

$U A C P$, Unilateral antegrade cerebral perfusion; $N A$, not available; $A C P$, antegrade cerebral perfusion; $L C C$, left common carotid artery; $T N D$, transient neurologic deficit; $P N D$, persistent neurologic deficit; $B A C P$, bilateral antegrade cerebral perfusion; $R A$, right axillary artery. ${ }^{*} P=.057$ versus other antegrade cerebral perfusion groups. $\dagger P=.06$ versus unilateral antegrade cerebral perfusion.

colleagues, ${ }^{10}$ examining 500 circles of Willis postmortem with computed tomographic angiography and found that $58.6 \%$ had anatomic variations that could cause cerebral hypoperfusion during UACP, with $35.6 \%$ missing a left posterior communicating artery. They cautioned that prolonged UACP, in the presence of circle of Willis variations, may lead to subtle but significant neurocognitive deficits, such as delirium and psychocognitive changes.

Clinical and anatomic findings thus suggest that a more patient-specific ACP strategy might optimize neurologic outcomes. UACP is acceptable for shorter intervals ( $<30-40$ minutes) if combined with moderate hypothermia. For prolonged ACP intervals, or if left cerebral oxygenation becomes significantly reduced during UACP, BACP should be considered.

An advantage of the trifurcated graft technique is that it facilitates creation of an elephant trunk in the proximal arch, where it is technically easier and avoids injury to the recurrent laryngeal nerve (Figure 1). In addition, the trifurcated graft technique has proved versatile in dealing with various arch anatomies and anomalies. For a laterally displaced left subclavian artery, a preoperative left carotid to subclavian bypass simplifies the ensuing TAR, requiring only a bifurcated graft to complete the repair. Alternatively, a separate 8- or 10-mm Dacron polyester fabric graft can be sewn to the left axillary artery, brought through the left 


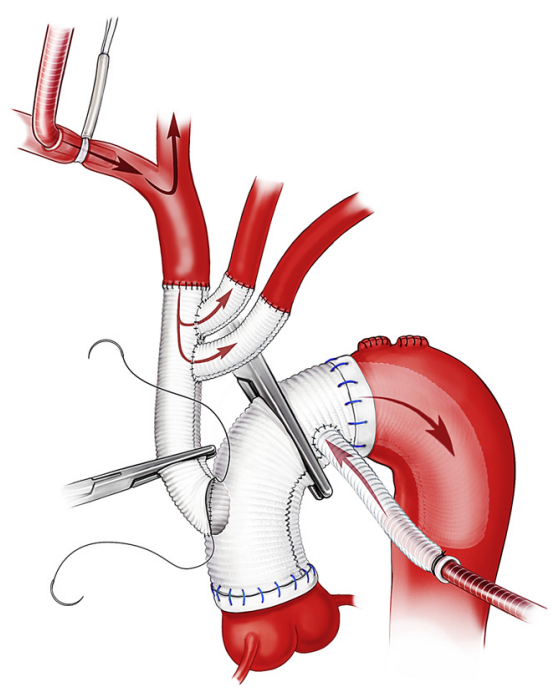

FIGURE 1. An example of trifurcated graft total arch reconstruction with elephant trunk anastomosis and side-arm graft for lower body perfusion.

thorax, and attached to a limb of the trifurcated graft during rewarming. For a left vertebral artery arising directly from the aortic arch, the size and patency of the right vertebral artery determine whether the arch reconstruction strategy should permit early reperfusion of the anomalous left vertebral artery along with the brachiocephalic vessels or whether it can be anastomosed at a later point in the procedure. A number of configurations are possible for the anomalous vertebral, including direct anastomosis to the left common carotid artery or anastomosing the left subclavian and anomalous left vertebral artery with a "button" of arch tissue to the larger limb of the trifurcated graft.

\section{DISCUSSION}

The trifurcated graft technique for TAR is a versatile method that easily accommodates variable arch anatomies while permitting continuous ACP without HCA. The technique can be applied to acute aortic pathologies and hybrid arch procedures, with concomitant or staged endovascular options. In cases of prolonged ACP and LBI, $\mathrm{BACP}$ and lower body perfusion can be performed without adding significant complexity to the procedure while conferring maximal cerebral, spinal, and lower body protection.

\section{References}

1. Spielvogel D, Strauch JT, Minanov OP, Lansman SL, Griepp RB. Aortic arch replacement using a trifurcated graft and selective cerebral antegrade perfusion. Ann Thorac Surg. 2002;74:S1810-4; discussion S1825-32.

2. Etz CD, Luehr M, Kari FA, Lin HM, Kleinman G, Zoli S, et al. Selective cerebral perfusion at $28^{\circ} \mathrm{C}$-is the spinal cord safe? Eur J Cardiothorac Surg. 2009;36: 946-55.

3. Kamiya H, Hagl C, Kropivnitskaya I, Böthig D, Kallenbach K, Khaladj N, et al. The safety of moderate hypothermic lower body circulatory arrest with selective cerebral perfusion: a propensity score analysis. J Thorac Cardiovasc Surg. 2007; 133:501-9.

4. Luehr M, Bachet J, Mohr FW, Etz CD. Modern temperature management in aortic arch surgery: the dilemma of moderate hypothermia. Eur J Cardiothorac Surg. 2014;45:27-39.

5. Bakhtiary F, Dogan S, Zierer A, Dzemali O, Oezaslan F, Therapidis P, et al. Antegrade cerebral perfusion for acute type a aortic dissection in 120 consecutive patients. Ann Thorac Surg. 2008;85:465-9.

6. Krähenbühl ES, Clément M, Reineke D, Czerny M, Stalder M, Aymard T, et al. Antegrade cerebral protection in thoracic aortic surgery: lessons from the past decade. Eur J Cardiothoracic Surg. 2010;38:46-51.

7. Zierer A, Risteski P, El-Sayed Ahmad A, Moritz A, Diegeler A, Urbanski PP. The impact of unilateral versus bilateral antegrade cerebral perfusion on surgical outcomes after aortic arch replacement: a propensity-matched analysis. J Thorac Cardiovasc Surg. 2014;147:1212-7; discussion 1217-8.

8. Angeloni E, Benedetto U, Takkenberg JJ, Stigliano I, Roscitano A, Melina G, et al. Unilateral versus bilateral antegrade cerebral protection during circulatory arrest in aortic surgery: a meta-analysis of 5100 patients. J Thorac Cardiovasc Surg. 2014;147:60-7.

9. Krüger T, Weigang E, Hoffmann I, Blettner M, Aebert H; GERAADA Investigators. Cerebral protection during surgery for acute aortic dissection type A: results of the German registry for acute aortic dissection type A (GERAADA). Circulation. 2011;124:434-43.

10. Papantchev V, Stoinova V, Aleksandrov A, Todorova-Papantcheva D, Hristov S, Petkov D, et al. The role of Willis circle variations during unilateral selective cerebral perfusion: a study of 500 circles. Eur J Cardiothorac Surg. 2013;44: $743-53$. 